\title{
Setting the mountain ablaze? The Royal Highland Festival in Bhutan from the semi- nomads' perspective
}

\author{
Jigme Wangdi ${ }^{1}$, Tashi Dorji ${ }^{2}$ and Kesang Wangchuk ${ }^{2 *}$
}

\begin{abstract}
A study was conducted to assess the effects of the Royal Highland Festival (RHF) from the perspective of yak herders in Laya, Bhutan. Sixty-six respondents were randomly selected from amongst the domicile herders who were regular visitors to the festival. A survey was carried out through a questionnaire with mixed questions. Herders' opinions suggest good progress of RHF as reflected by improved community vitality and networking with stakeholders. Tourists, both international and domestic, were the major contributors to the income of yak herders during the festival. Livestock products were the biggest income earner, followed by homestays. Herders were encouraged to produce more quantities of livestock products and desired to diversify yak products. Animal shows were adequate and encouraged breed improvement. The grazing resources and the environment were unharmed by the presence of animals in the festival. However, yak herders expressed concerns over the lack of skills and knowledge for yak product diversification and management of festival waste. Herders felt the need to shift the festival venue to benefit highlanders in other areas of Bhutan. The study recommends authorities to consider imparting skills to Laya communities on developing diverse and value-added yak products. Homestay owners require more capacity to manage and maintain farmhouses with proper sanitation. Effective management of festival wastes calls for a farsighted plan. Finally, to inculcate a sense of pride and ownership, the communities of Laya must be empowered to self-organize the festival, while government authorities should consider shifting the festival venue to other highland areas.
\end{abstract}

Keywords: Hindu Kush Himalayas, Tourism, Diversification, Socio-economic, Yak herders

\section{Introduction}

Festivals and events have social and cultural significance with a festive character depicting a public celebration of some concept or fact (Janiskee 1980). They hold a long historical trajectory and exemplify the cultures and traditions of various pasts (Quinn 2009). The importance of festivals and events is well-reflected in the ways people set aside time and space for them (Turner 1982). Festivities attract people from all groups; hence, festivals and events reinforce the ties and harmony between people,

\footnotetext{
*Correspondence: kesang.wangchuk@icimod.org

${ }^{2}$ International Center for Integrated Mountain Development, Kathmandu, Nepal

Full list of author information is available at the end of the article
}

improve social lives, and connect people with cultural heritage. Matheson (2005) finds festivals and events to encapsulate a sense of place and peoples' identities. With strategic planning and well-defined goals supported by the right partners and resources, community festivals can make a significant contribution to rural development through the creation of jobs and support to local businesses (Irshad 2011). Many researchers attribute the recent proliferation of festivals and events to their tourism potential (Prentice and Andersen 2003; Gursoy et al. 2004; Quinn 2009).

In the Hindu Kush Himalayas (HKH), festivals and events are integral to mountain society. The multicultural diversity results in different festivals across the 
Himalayas. Largely related to religion and culture (Honeyguide to the mountains 2021), most cultural festivals and events in the $\mathrm{HKH}$ promote societal growth and reinforce community vitality through a range of exhibitions, cultural performances, and displays of traditional artworks (Himalayan Voices 2021). While the age-old festivals continue to flourish, new cultural festivals are increasing within the Himalayan region (Honeyguide to the mountains 2021). The recent proliferation could be associated with communities seeking to reassert their identities that face cultural erosion by rapid globalization processes (Fjell 2007). This is best exemplified by "Beef festivals" that assert the cultural rights and identity of Dalit people in India (Natrajan 2018) and "Easter Festival" that assert the identity of Sami people in Norway (Jaeger and Mykletun 2013). The growth in the number of these festivals also reflects the struggles to overcome challenges of new social, economic, and political environments (Picard and Robinson 2006). Studies that have evaluated the impacts of the festival on rural economies report both social and economic impacts (Mair and Duffy 2018; Alves et al. 2010; Gibson and Stewart 2009; Chhabra et al. 2003). However, a few studies found a social impact to extend beyond economic impact (Irshad 2011; Chhabra et al. 2003). Unlike in the past, modern festivals are pursued to bring about economic benefits to the rural communities (Walo et al. 2011; Mbaiwa and Sakuze 2009).

Amongst the Himalayan countries, Bhutan has been steadfast in promoting new festivals. The Royal Highland Festival (RHF) is the most recent in Bhutan and has grown popular in a short period (RIM 2018). RHF aims to maintain the existence of highland communities, preserve highland culture and identity, and improve the socio-economic condition of highlanders (Royal Institute of Management 2018; Gasa Dzongkhag 2017). Four years have passed since RHF began in 2016, and there has been only one study by Bhutan's Royal Institute of Management (RIM) that investigated the festival experiences of visitors (RIM 2018). Although the study covered a large range of respondents, it spreads thinly in presenting salient findings and recommendations. Specifically, RIM's study falls short of an in-depth investigation into the RHF's effects on the yak herding communities of Laya. In most studies on festivals, the socio-cultural impact is an under-researched field (Asvanyi and Jaszberenyi 2017).

Livestock herding as the mainstay of highlanders in Bhutan is stressed through interventions targeted to ease the drudgery of herding yak in the harsh environment. The RHF was first introduced on 16 October 2016 to commemorate the birth of the Prince, 400 years of the Founder of Bhutan, and the birth year of Guru Rimpoche who introduced Buddhism in Bhutan (Gasa Dzongkhag 2019). RHF is a very important intervention to make the highland environment attractive, possibly through enhancement of the economic well-being of highland communities, which is expected to lure the future generation into practising the highland way of life. Yet, there is a lack of evidence to suggest if RHF has met the intended purpose. Hence, this study seeks to fill the void by carrying out an in-depth analysis of the RHF effects on yak herding communities of Laya. The study objective was to generate science-based information on the critical impacts of RHF at various levels from the perspective of the yak herding community in Laya. The information is envisioned to help authorities in improvising the festival to accomplish the long-term goal.

\section{Study site}

The RHF is organized in Laya, located in the northwestern part of Gasa District. Laya is one of the most remote places in Bhutan. Layaps, the inhabitants of Laya, live a semi-nomadic lifestyle. The Laya community is known for its tradition of polyandry to keep families and property together, although this custom is declining. The community also has a tradition of child marriage. They rear yaks and also keep small ponies. Due to the cold weather, few crops are planted. The community earns a good income from the sale of caterpillar fungus, which is an important part of traditional Chinese medicine.

The main site of the festival is Longang at an altitude of about 4000 masl. Laya has a relatively high yak population of 6398 (DoL 2020). It is inhabited by a small population of about 1108 in 213 households (Gasa Dzongkhag 2019), mostly dependent on yak farming. Laya experiences moderately cold and wet summers (June to August), followed by freezing winter (November to April). Herdsmen practice transhumant agro-pastoralism and migrate to lower elevations in winter and vice versa in summer.

\section{Description of RHF}

The festival is a 2-day annual event held every fall. The RHF begins with Buelwa (a traditional gift offering) and Auley (traditional epic poem/song recitation). This is a testament to the loyalty and respect of the Laya community for the dynamic and visionary leadership of the Bhutanese monarchs. People from all groups, including representatives of highland communities and tourists, gather in Laya to celebrate the festival. The festival introduces the yak-based life, the presence of a unique nomadic culture, and a peaceful environment. Government agencies involved in the RHF organization are the Gasa Administration, the Ministry of Agriculture and Forest, and His Majesty's Secretariat. RHF's main attractions include traditional folk dance, yak, mastiff performances, Laya run, traditional sporting events, and entertainment 
by the Bhutanese entertainment industry. In addition to promoting knowledge-sharing between professionals and highlanders, the festival raises awareness of highland culture, health (animals and humans), innovation, waste management, and hygiene promotion. Other highlanders participating in the festival are from the Bhutanese districts of Bumthang, Haa, Lhuentse, Paro, Thimphu, Trongsa, Trashigang, Trashiyangtse, and Wangdue. With the facilitation of the International Centre for Integrated Mountain Development (ICIMOD), the highlanders of neighbouring Sikkim and Nepal also participate in the festival, exhibiting a variety of highland products and knowledge.

\section{Methodology}

\section{Selection of respondents}

For selecting respondents, we employed the snowball sampling technique (Biernacki and Waldorf 1981) at two stages. In the first stage, researchers, development workers, and local government bodies were consulted on the type of respondents that the survey should cover. In the second stage, the community leaders were consulted who recommended residents, actively engaged in the festival, as potential respondents of the survey interviews. This led to a set of criteria for the selection of respondents. The criteria required a respondent to be a domiciled resident of the Laya yak herding community and a regular visitor to RHF. Regardless of gender, the criteria resulted in the selection of 66 key respondents from amongst the yak-herding members in 2019. The respondents comprised over $71 \%$ males and approximately $29 \%$ females. Most respondents being males could be ascribed to men comprising the larger portion of the human population in Laya (Gasa Dzongkhag 2019). The greater number of men at the festival site indicated that men take part in public events such as RHF while the domestic chores leave less time for women to engage in other activities. Besides yak herding, yak herdsmen are also reported to engage more in off-farm activities (Wangchuk and Wangdi 2015). Figure 1 presents the characteristics of respondents.

\section{Field interview}

Respondents were interviewed during the RHF in October 2019. The qualitative data was collected through a questionnaire survey with mixed questions. All questions were directed to the respondents whose answers represented their perceptions. The authors conducted face-toface interviews at the festival venue, and respondents answered the survey questions. The pre-tested semistructured questionnaire was strategically divided into five sections to understand the key indicators of successful RHF from the respondents' perspective. Questions sought respondents' opinions on the improvement of
RHF over the years, awareness of the RHF's objective, and the current duration of RHF. The authors collected the opinions of respondents on the importance of RHF to yak herders. Respondents also offered information on the economic benefits of the RHF and the community vitality in the highland. The questions sought information on respondents' sources of income and their contributions. Respondents identified the strength and weaknesses of RHF from a livestock perspective. In the entire survey, the qualitative data represented the respondents' perceptions.

Throughout the questionnaire, the validity and reliability of the information were defined by the 3-point Likert scale (Likert 1932), which was used to simplify the information. A 3-point scale was used against the commonly applied 5-point scale since the validity and reliability of the information are independent of the scale points employed by Likert-type items (Jacoby and Mitchell 1971). This scale was used to collect information about whether respondents agreed, disagreed, or did not know the answers to the survey questions.

\section{Data analysis}

The survey data were processed in Microsoft Excel 2019. The data were cleaned and validated before exporting to the Statistical Packages for Social Science (SPSS) version 25 (IBM 2009). The data were descriptively analysed in SPSS. Frequencies and percentages were used to summarize and interpret qualitative information.

\section{Results and discussion}

\section{Conduct of RHF and festival participants}

RHF has progressed over the years and received a highly positive response from international tourists (RIM 2018). RIM (2018) reported the growing popularity of RHF, and both highlanders and international tourists were highly satisfied with the festival. The popularity could be ascribed largely to the uniqueness of the celebration, having a mix of cutting edge and events such as conventional offerings, conventional sports contest, and Laya run. The popularity of RHF also underscores the concerted and collaborative efforts of government agencies and local governments of the Gasa District.

The respondents' opinions displayed in Table 1 showed that not all respondents were mindful of the objectives of RHF. It implies that despite 4 years of RHF, the organizers are yet to accomplish full communication of the quintessence of RHF to a more extensive populace in Laya. It could also be inferred as a certain smaller section of highlanders failing to consider RHF important. Hence, there is an inconsistency to a common presumption that highlanders view RHF as necessary to their survival and sovereignty. More efforts are needed from festival organizers to reiterate the objectives of the RHF 


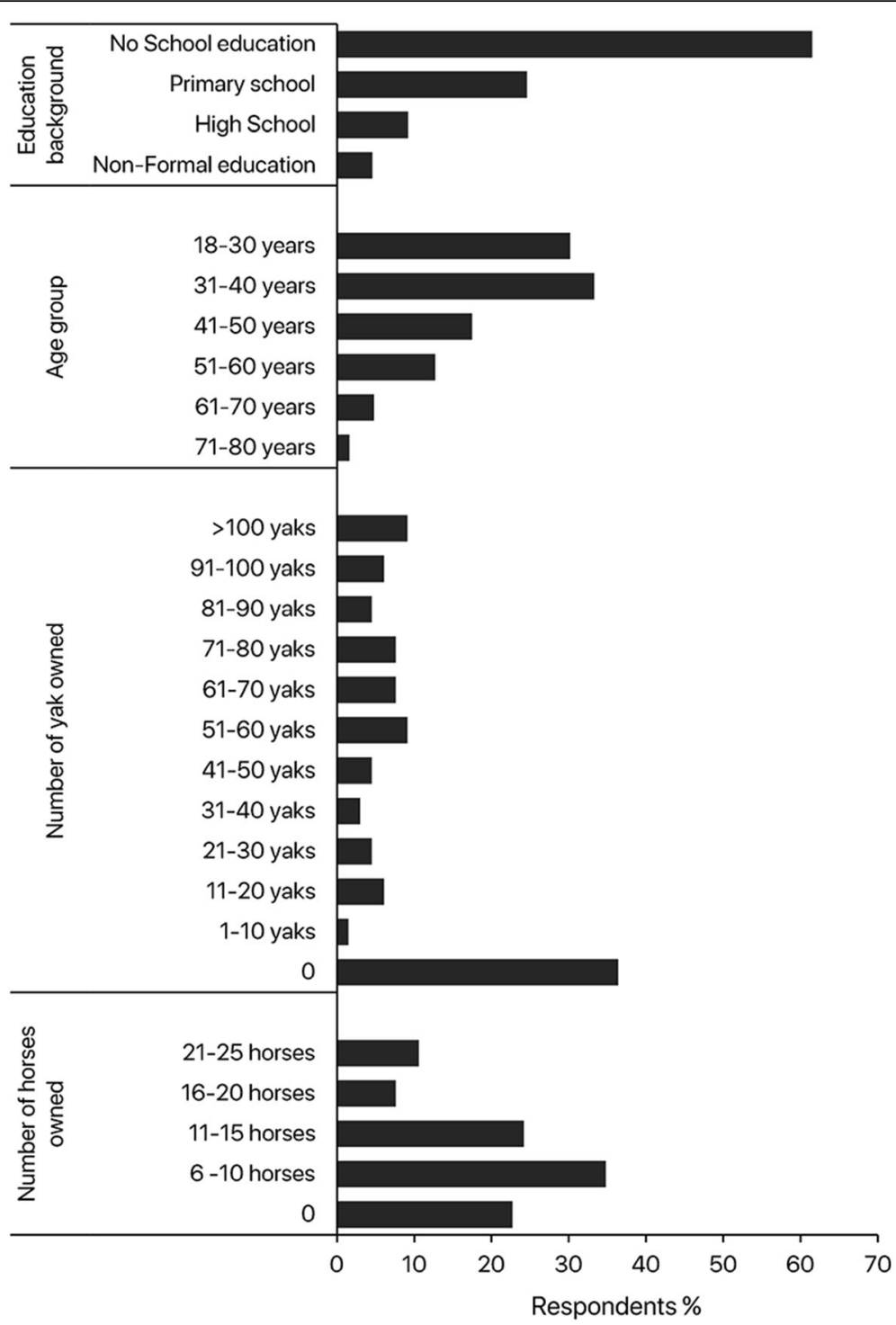

Fig. 1 Characteristics of respondents and livestock owned

celebration through the community leaders and local governments.

The festival duration of 2 days was found adequate, in contrast to a smaller section of respondents who found the duration inadequate. The inadequate duration felt by a small proportion of respondents may appear insignificant, but it signals a need to re-examine whether the current duration will be adequate in the future. This is

Table 1 General opinions of herders on RHF

\begin{tabular}{llll}
\hline & Yes & No & Do not know \\
\hline Has RHF improved over the years? & 77.3 & 16.7 & 6.00 \\
Are you aware of the objectives of RHF? & 79.0 & 7.60 & 13.4 \\
Is the festival duration adequate? & 65.2 & 31.0 & 3.80 \\
\hline
\end{tabular}

because as the festival grows with time and sees a huge inflow of participants in the future, it may have to improvise to include more events, for which 2 days may not be adequate to meet the demands of future visitors and participants.

Amongst the visitors outside the Gasa District, almost $30 \%$ participated in the Laya run, followed by government officials (Fig. 2). It indicates Laya run as one of the main attractions to participants outside the district. The Laya run is a $25-\mathrm{km}$ race to the festival site and marks the beginning of the RHF. Since the run is adventurous and takes participants across beautiful scenery, it attracts participants from all groups and has grown popular with international tourists over a brief period. Contrary to the prediction of RIM (2018) that the number of runners will decline in the future, the recent official record shows 


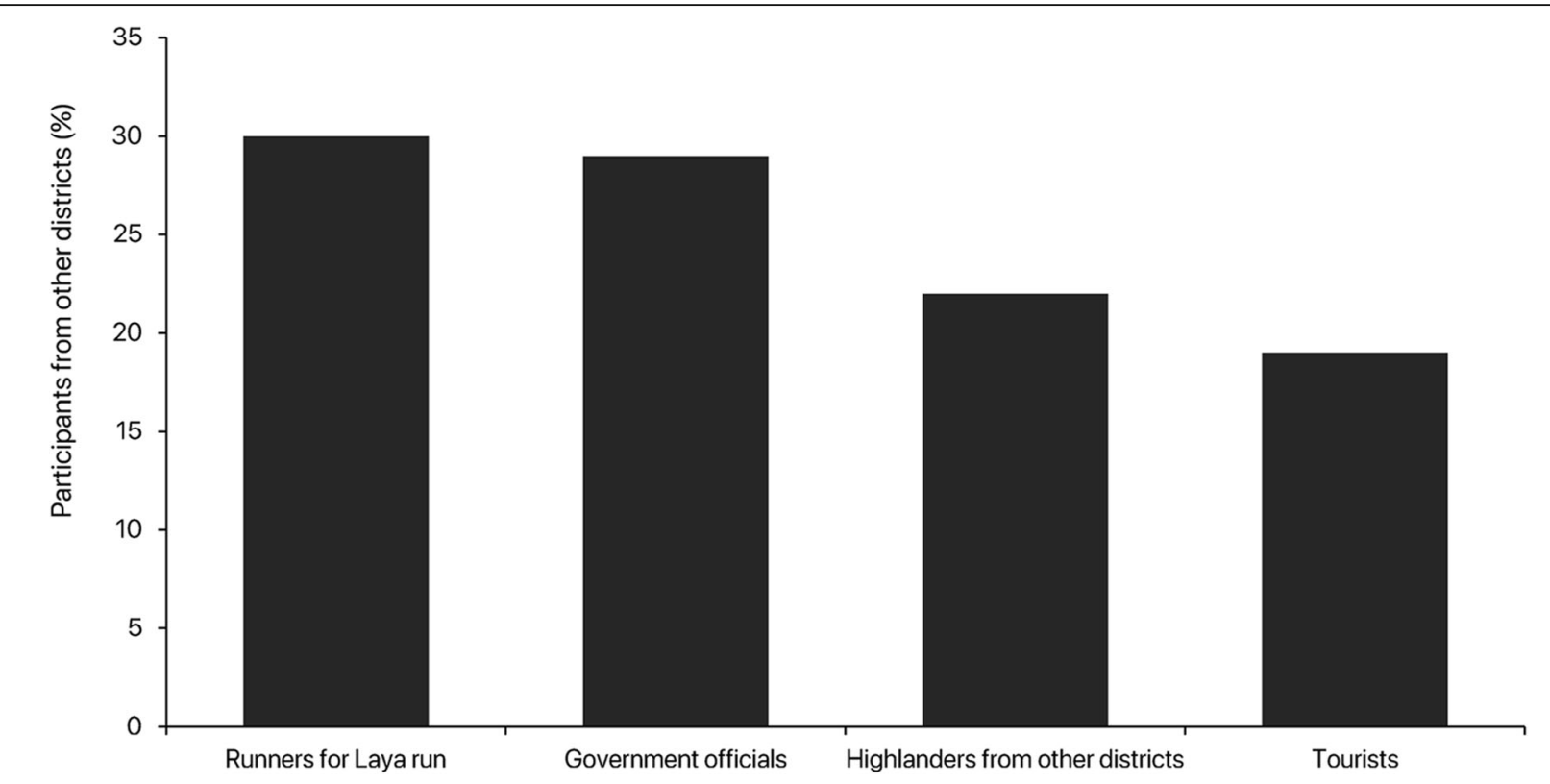

Fig. 2 Proportion of participants outside Gasa District

an increase in 2019 (Gasa Dzongkhag 2019), suggesting the growing popularity of Laya run to the domestic and foreign participants alike.

\section{Economic effects of RHF}

The festival capitalizes on economic opportunities to encourage and motivate highlanders to continue the culture and tradition of yak herding. Although this study was unable to uncover how RHF contributed to boosting the economy on several levels, a few key variables were used to comprehend the economic effect of the festival. Tourists in general were the biggest contributor to the total income of yak herders (Fig. 3). However, the disaggregated data showed international tourists as a bigger contributor than domestic tourists. It reflects the growing popularity of RHF with international tourists who generally are keen to explore and experience the traditional and cultural life of rural Bhutan.

Livestock products were the most important source of income, followed by homestays. The livestock products are mainly meat and dairy products of yak that enjoy high demand by consumers, mainly the Bhutanese. The high demand results from the small quantity of supply. Some common yak products are fresh and dried meat, soft and hard cheese, fermented cheese, curd, etc. Livestock products not only help to combat food insecurity and malnutrition in the mountains but also generate cash incomes to reduce poverty and improve resilience (Maltsoglou and Taniguchi 2004; Gautam 2002). However, livestock product diversification is challenged by the lack of skills and knowledge. Wangchuk et al. (2019) reported a similar issue as the stumbling block to an enhanced income of highlanders in western Bhutan.

The homestay was the second most important source of income and suggests spending by festival visitors on homestays in Laya. Homestays have picked up since the start of RHF in 2016. Macek (2012) reported a homestay programme as a suitable and viable community economic development tool in rural settlements. A good earning from homestays reflects the growing interest of visitors to spend on experiencing the unique traditional Bhutanese hospitality in a typical farmhouse of seminomads in Bhutan. Close interaction with highland people and experiencing their lifestyle and culture were found as the unique selling point of RHF (RIM 2018). Further, the homestays are offered at a reasonable price from $\mathrm{Nu} .1000$ to $\mathrm{Nu} .2000$ ( $₫$ US\$ 15-30 a night) inclusive of breakfast and dinner (Gasa Dzongkhag 2019). Handicraft was the least important source, and only about $5 \%$ of respondents earned income from handicraft sales. This is a total contrast to urban Bhutan where handicraft business is reported to be lucrative, allowing a business person to earn over US\$ 400.00 in a day during the peak tourist season (Business Bhutan 2017).

Portering and transportation were the third important source of income. Most respondents owned horses, highlighting the importance of equines (mules and donkeys) in the lives of highlanders in Laya. For remote mountain communities that have difficult access to necessities, horses are more of a lifeline. It is worth noting that over the years, with growing tourism, the use of horses for transporting tourist goods has become a lucrative business venture for highlanders (Daily Bhutan 2020). A single 


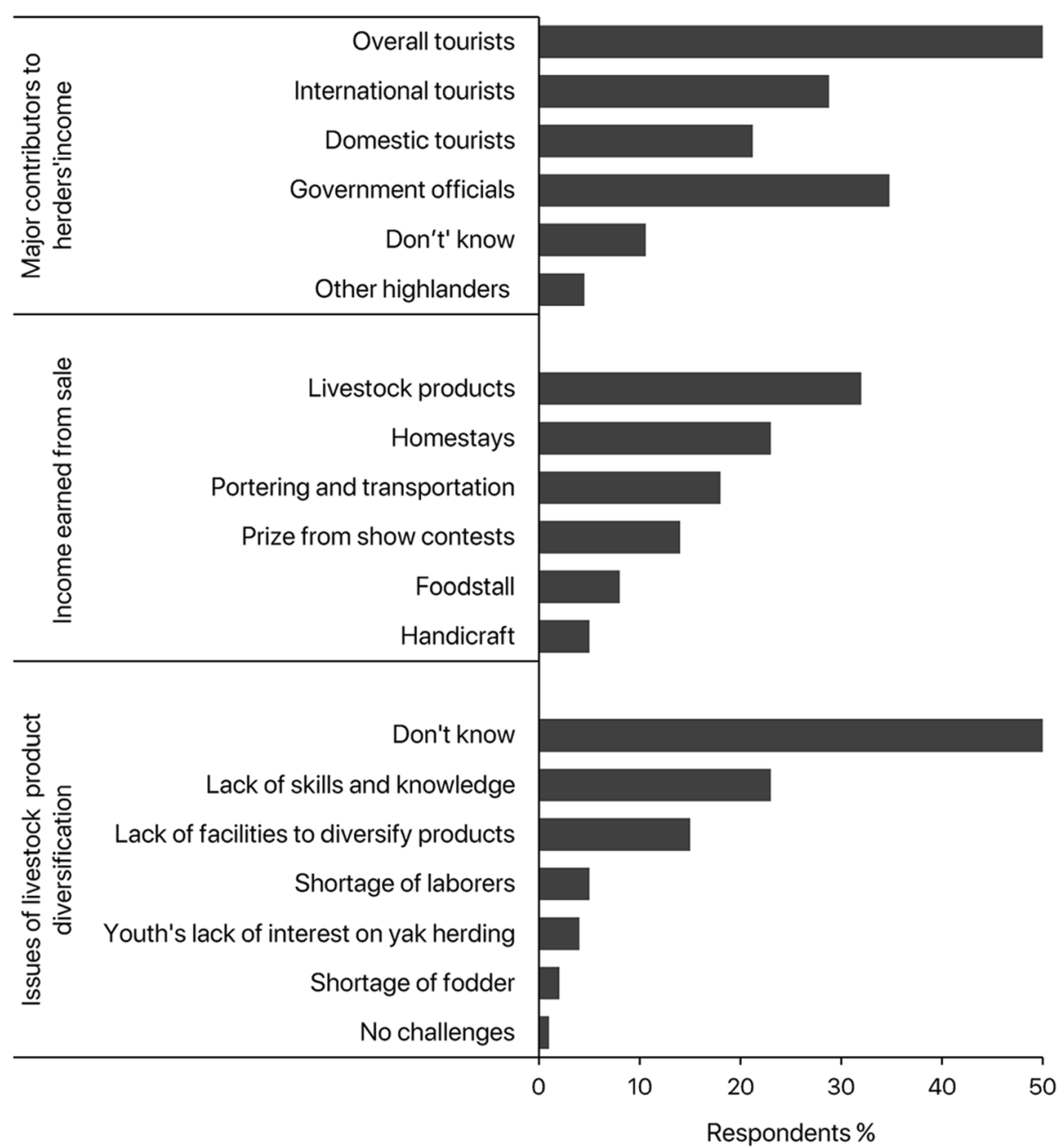

Fig. 3 Income sources, contributors to the income, and issues of livestock product diversification of yak herders

horse is hired out at the rate of $\mathrm{Nu} .800(\simeq$ US\$ 11) per horse per day, which earns a monthly income of $\mathrm{Nu}$. 24, 000 ( $₫$ US\$ 350) from a single horse (Gasa Dzongkhag 2017), which explains why a large proportion of respondents owned a good number of horses in Laya. Currently, Laya has 1597 equines, the highest amongst 205 administrative blocks in Bhutan (DoL 2020).

\section{Social effects of RHF}

RHF has improved over the last 4 years, which has enhanced community vitality and improved networking (Table 2). It highlights the positive effect of RHF on fostering the vitality of community life that is necessary for sustaining core values and achieving the goals of Gross National Happiness (GNH) in Bhutan (Kinga 2008). The festival brings people from remote regions of Gasa together, sparking joy and enthusiasm of meeting fellow herders after a long time. RHF offers an opportunity for improved networking for Laya herders to connect with other highlanders from within and outside Bhutan. The display of a yak product "dog chew" at the festival by a herder from Nepal was a new experience for the Laya herders. It was through interactions that the Laya herders learned how yak milk could fetch a higher price if it is processed into hard cheese suited for pet dogs in the USA. Similar experiences were shared amongst the herders of yak-rearing countries in Asia during the Sixth International Yak Conference in China, where the conference recommended establishing local and regional yak herders' networks (Dorji et al. 2019). It exemplifies how networking could be vital in providing the ability to collaborate with experts for growth and success in any venture (Fredin 2018). In this context, RHF serves as a forum for Bhutanese and non-Bhutanese highlanders to exchange new entrepreneurship ideas, particularly on the development of yak products.

Although most respondents were undecided on producing more yak products, the festival has encouraged herders to produce more quantities of these products for RHF. The yak products fetch good income and 
Table 2 Perceived social effects of RHF in Laya

\begin{tabular}{|c|c|c|c|}
\hline \multirow[t]{2}{*}{ Social variable } & \multicolumn{3}{|c|}{ Respondents (\%) } \\
\hline & Yes & No & Do not know \\
\hline \multicolumn{4}{|l|}{ Community impacts of RHF } \\
\hline - The conduct of RHF has improved over the years. & 77.3 & 16.7 & 6.00 \\
\hline - RHF has strengthened community vitality. & 93.9 & 0.00 & 6.10 \\
\hline - RHF has improved the networking with ex- and in-country yak herders. & 77.3 & 1.50 & 21.2 \\
\hline \multicolumn{4}{|l|}{ Livestock impacts of RHF } \\
\hline - RHF encourages to produce more yak products. & 39.4 & 12.1 & 48.5 \\
\hline - I want to diversify livestock products and handicraft for RHF. & 69.7 & 6.10 & 24.2 \\
\hline - Livestock activities are adequate in RHF. & 48.6 & 16.9 & 34.5 \\
\hline -Animal shows were beneficial. & 48.4 & 21.7 & 29.9 \\
\hline -RHF will help to improve yak and livestock breeds. & 65.2 & 1.50 & 33.3 \\
\hline \multicolumn{4}{|l|}{ Environmental impacts of RHF } \\
\hline - RHF is important to yak herding. & 97.0 & 1.50 & 1.50 \\
\hline - RHF harms grazing resources. & 9.10 & 53.0 & 37.9 \\
\hline - RHF harms the environment. & 4.50 & 60.6 & 34.8 \\
\hline - Waste management is a concern in RHF. & 53.0 & 4.50 & 42.4 \\
\hline \multicolumn{4}{|l|}{ RHF in future } \\
\hline - It is important to organize a similar festival in other parts of Bhutan. & 83.1 & 1.53 & 15.4 \\
\hline - RHF is encouraging the young generation to take up yak farming. & 82.0 & 0.00 & 18.0 \\
\hline - RHF will meet its objectives. & 84.0 & 0.00 & 16.0 \\
\hline
\end{tabular}

encourage herders to increase their herd sizes (Dorji et al. 2020). Since the selling of yak products was the largest earner in RHF, the respondents wish to diversify products along with handicrafts. It suggests the herders' interest in increasing income from livestock items.

The number of livestock events during the festival was also deemed sufficient by most respondents. The principal highlights of livestock events are animal parades, animal contests, and horse races (Gasa Dzongkhag 2017). The parade is an emblem of the festival, and decorated animals are paraded on the festival ground with the traditional music. Amongst livestock activities, animal shows were the most beneficial, as they offered an opportunity to showcase good breeds of domestic animals. It supports the exhibition's aim to educate participants about the value of preserving animals of good quality. Further, the recognition of good breeds could encourage the herding community to conserve indigenous animals. Thus, most respondents agree that RHF will help to develop animal breeds in the future.

RHF is critical to yak herding. The significance of RHF to yak herding lies in the fact that the festival is largely livestock-based, and numerous veterinarians and animal breeders gather at the festival, bringing with them important livestock services. The festival is also attended by numerous development agencies that are actively engaged in rural development missions. In such a scenario, RHF could potentially draw the attention of these agencies to the issues of yak herding and generate interest to intervene towards saving the deteriorating herding culture.

Despite having several types of animals in the festival, no harmful effects had occurred to the grazing resources and the environment. This reflects the well-planned and efficient management of resources by the festival organizers. The festival requires the animals to be tethered and fed at the festival site. On the contrary, many have concerns about waste management during the festival. Although the festival provides good memories, it is the local community and authorities who are left to manage the festival waste. The main concern could be on managing non-biodegradable wastes.

It has been over fours of RHF being held in Laya and respondents felt the need to shift the festival venue to other parts of Bhutan's highland that are facing similar issues. It concurs with the recommendation of RIM (2018) that options must be explored to locate the festival venue to other highland areas. A shift in venue could have two positive effects. First, it will help boost the economies in other regions of the highlands. Second, it could generate a sense of the importance of yak herders' presence in highlands. RHF seems to encourage the young generation to take up yak farming despite their dwindling population after Cordyceps (caterpillar fungus) collection started in 2004 (Wangchuk and Wangdi 
2015). Considering increasing access to education and other income-earning opportunities causing rural outmigration, it is premature to infer that RHF could lure young herders into practising yak herding in the future.

\section{Policy recommendations}

The study showed a poor diversity of yak products available at the festival. Hence, focussed attention is needed on yak product diversification, which could contribute to enhancing the appeal of the festival. In achieving this, the government may consider it a priority to impart skills and capacity development training to the herding community of Laya. In particular, the handicraft business has not yet realized its potential. However, a prior study is necessary to understand the opportunities and guide the herding community to develop new and diverse products.

Homestays have great potential to earn more income for the residents of Laya. As the visitors and tourists have direct interactions with the host, homestays could be looked upon as a gateway to community-based tourism in Laya. Nonetheless, there are shortcomings such as poor sanitation, poor hygiene, and poor food diversity. The tourism stakeholders, together with the local government of Laya, may consider addressing these issues as an immediate priority to promoting homestay entrepreneurship in Laya.

Littering and waste management are likely to demand special attention. Organizers may adopt a renewed approach of public education to instil a sense of responsibility amongst festival visitors on waste management. Finally, for long-term sustenance, it is essential to empower communities of Laya to self-organize the festival, while government agencies should consider shifting the festival venue to other highland areas.

\section{Conclusion}

The perceptions captured by this study largely represent that of the male residents. The RHF has both economic and social impacts on yak herding communities in Laya. The social impact extends beyond economic impact. There are a few important areas of RHF that need the attention of organizers. Although livestock products are the biggest income earner, the diversity of these products is rather poor. Dairy products are limited largely to butter and cheese. Despite 4 years of holding the festival, the authorities have made no attempts to address this issue. There is an opportunity to enhance income from livestock products. A pragmatic strategy lies in dairy product diversification, which should target a wide range of customers beyond Bhutanese. Homestays are in their infancy, and there is a need to build the capacity of households to manage and maintain homestays with proper sanitation and hygiene. As Bhutan continues to see a surge in tourist arrival annually, there will be a great demand for decent homestays in rural areas.

\section{Abbreviations \\ GNH: Gross National Happiness; HKH: Hindu Kush Himalaya; RHF: Royal Highland Festival; RIM: Royal Institute of Management}

\section{Acknowledgements}

The authors gratefully acknowledge the Livestock Sector of Gasa Dzongkhag for their assistance in carrying out the survey.

The authors are thankful to ICIMOD for encouragement and support. This study was supported by core funds of ICIMOD contributed by the

Governments of Afghanistan, Australia, Austria, Bangladesh, Bhutan, China, India, Myanmar, Nepal, Norway, Pakistan and Switzerland. We are indebted to the reviewers for their constructive suggestions and inputs.

\section{Disclaimer}

The views and interpretations in this publication are those of the authors They do not imply the expression of any opinion by ICIMOD concerning the legal status of any country, territory, city or area of its authorities, or concerning the delimitation of its frontiers or boundaries, or the endorsement of any product.

\section{Authors' contributions}

Jigme Wangdi conceptualized the research and wrote the manuscript. Kesang Wangchuk contributed to the concept, designed the survey questionnaire, analysed the data, and wrote the manuscript. Tashi Dorji contributed to the concept and offered scientific advice to improve the manuscript. The authors read and approved the final manuscript.

\section{Funding}

The authors' travel to the field was funded by the Department of Livestock, Bhutan.

Availability of data and materials

Research data, collected through the survey, is available on demand.

\section{Declarations}

\section{Ethics approval and consent to participate}

The research was approved by the Ethical Committee of the Department of Livestock, Bhutan. Consents were sought from respondents who agreed to participate in the research survey.

\section{Consent for publication}

Consent for publication was obtained from the Research and Extension Division of the Department of Livestock.

\section{Competing interests}

The authors declare that they have no competing interests.

\section{Author details}

${ }^{1}$ Department of Livestock, Ministry of Agriculture and Forests, Thimphu, Bhutan. ${ }^{2}$ International Center for Integrated Mountain Development, Kathmandu, Nepal.

Received: 7 January 2021 Accepted: 5 March 2021

Published online: 31 March 2021

\section{References}

Alves, H., A.M. Campon-Cerro, and A.V.F. Martins. 2010. Impacts of small tourism events on rural places. Journal of Place Management and Development 3 (1) 22-37. https://doi.org/10.1108/17538331011030257.

Asvanyi, K., and M. Jaszberenyi. 2017. The role of rural cities' festivals in the development of regions. The Central European Journal of Regional Development and Tourism 9 (3): 177-187.

Biernacki, P., and D. Waldorf. 1981. Snowball sampling. Sociological Methods \& Research 10 (2): 141-163. https://doi.org/10.1177/004912418101000205.

Business Bhutan (2017). Handicraft shops do lucrative business. Available at: https://www.businessbhutan.bt/2017/08/16/handicraft-shops-do-lucrativebusiness. Accessed 3 Mar 2021. 
Chhabra, D., E. Sills, and F.W. Cubbage. 2003. The significance of festivals to rural economies: Estimating the economic impacts of Scottish highland games in North Carolina. Journal of Travel Research 41 (4): 421-427. https://doi.org/1 $0.1177 / 0047287503041004012$

Daily Bhutan (2020). Horses and mules - Lifeline for nomads living in the mountains of Lingzhi. Available at: https://www.dailybhutan.com/article/ horses-and-mules-lifeline-for-nomads-living-in-the-mountains-of-lingzhi. Accessed 9 Dec 2020

DoL. 2020. Livestock statistics 2019. Thimphu: Department of Livestock, MoAF.

Dorji, N., M. Derks, P.W.G. Groot Koerkamp, and E.A.M. Bokkers. 2020. The future of yak farming from the perspective of yak herders and livestock professionals. Sustainability 12: 1-15. https://doi.org/10.3390/su12104217.

Dorji, T., Ismail, M., and Long, R. (2019). Yak our identity: Himalayan herders raise concerns at International Yak Conference. Available at: https://www.icimod. org/yak-are-our-identity-himalayan-herders-raise-concerns-at-international-ya k-conference. Accessed 26 Feb 2021

Fjell, L. 2007. Contemporary festival: Polyphony of voices and some new agents. Studia Ethnologica Croatica 19: str. 129-149, Zagreb.

Fredin, N. (2018). The importance of networking. Available at: https://www. cgspectrum.com/blog/the-importance-of-networking. Accessed 29 Dec 2020

Gasa Dzongkhag. 2017. Royal Highland Festival. Ministry of Agriculture and Forests, Gasa, Bhutan.

Gasa Dzongkhag. (2019). Dzongkhag Administration, Gasa. Available at: http:// www.gasa.gov.bt/index.php/gewogs/laya. Retrieved on 8th December 2020

Gautam, P. 2002. Mountain farming and policies: Nepalese perspective. Munich: GRIN Verlag.

Gibson, C., and A. Stewart. 2009. Reinventing rural places: The extent and impact of festivals in rural and regional Australia. Wollongong: University of Wollongong, Australia.

Gursoy, D., K. Kim, and M. Uysal. 2004. Perceived impacts of festivals and special events by organizers: An extension and validation. Tourism Management 25 (2): 171-181. https://doi.org/10.1016/S0261-5177(03)00092-X.

Himalayan Voices (2021). Factsheet. http://himalayanvoices.org/?q=explore/fa ctsheets/culture/442. Accessed 24 Feb 2021

Honeyguide to the mountains (2021). 10 amazing festivals in the Himalayas. Available at: https://honeyguideapps.com/blog/10-amazing-festivals-in-thehimalayas. Accessed 24 Feb 2021

IBM. 2009. Statistical Package for Social Science. SPSS Inc., Chicago.

Irshad, H. 2011. Impacts of community events and festivals in rural places. Rural Development Division, Alberta Agriculture and Rural Development, Government of Alberta.

Jacoby, J, and Mitchell, M. 1971. Three-point Likert Scales are Good Enough. Journal of Marketing Research 8: 495-500.

Jaeger, K., and R. Mykletun. 2013. Festivals, identities, and belonging. Event Management 17 (3): 213-226. https://doi.org/10.3727/152599513X137088633 77791.

Janiskee, R. 1980. South Carolina's harvest festivals: rural delights for day-tripping urbanites. Journal of Cultural Geography 1 (Fall/Winter): 96-104.

Kinga, S. 2008. Reciprocal exchange and community vitality: The case of Gortshom Village in Eastern Bhutan, Proceedings of the Third International Conference on Gross National Happiness, 31-64. Thimphu: The Centre for Bhutan Studies.

Likert, R. 1932. A Technique for the Measurement of Attitudes. Archives of Psychology 140: 1-55.

Macek, I.C. 2012. Homestays as livelihood strategies in rural economies: The case of Johar Valley, Uttarakhand, India. MSC thesis. USA: University of Washington.

Mair, J., and M. Duffy. 2018. The role of festivals in strengthening social capital in rural communities. Event Management 22 (6): 875-889. https://doi.org/10.372 7/152599518X15346132863229.

Maltsoglou, I., and K. Taniguchi. 2004. Poverty, livestock and household typologies in Nepal. Kathmandu: Agricultural and Development Economics Division, The Food and Agriculture Organization of the United Nations.

Matheson, C.M. 2005. Festivity and sociability: A study of a Celtic music festival. Tourism Culture \& Communication 5 (3): 149-163. https://doi.org/10.3727/1 09830405774545035.

Mbaiwa, J.E., and L.K. Sakuze. 2009. Cultural tourism and livelihood diversification: The case of Gcwihaba Caves and XaiXai village in the Okavango Delta, Botswana. Journal of Tourism and Cultural Change 7 (11): 61-75. https://doi. org/10.1080/14766820902829551.
Natrajan, B. 2018. Cultural identity and beef festivals: Toward multiculturalism against caste. Contemporary South Asia 26 (3): 287-304. https://doi.org/10.1 080/09584935.2018.1504000.

Picard D, Robinson M. 2006. Remaking worlds: festivals, tourism and change. In: Picard D, Robinson M (eds) Festivals, tourism and social change: remaking worlds. Clevedon, Channel View 1-31.

Prentice, R., and V. Andersen. 2003. Festival as creative destination. Annals of Tourism Research 30 (1): 7-30. https://doi.org/10.1016/S0160-7383(02)00034-8.

Quinn, B. 2009. Festivals, events, and tourism. In The SAGE handbook of tourism studies, ed. T. Jamal and M. Robinson, 483-504. SAGE Publications Ltd. https://doi.org/10.4135/9780857021076.n27 APA

RIM. 2018. A visitor experience report of the 2018 Royal Highland Festival (draft) Semtokha: Royal Institute of Management, Thimphu, Bhutan.

Turner, V. 1982. Introduction. In Celebration: Studies in festivity and ritual, ed. V. Turner, 11-29. Washington, D.C.: Smithsonian Institution Press.

Walo, M., A. Bull, and H. Breen. 2011. Achieving economic benefits at local events: A case study of a local sports event. Festival Management and Event Tourism 4 (3): 95-106.

Wangchuk, K., T. Dorji, J. Wangdi, M. Wurzinger, and W. Zollitsch. 2019. Caught in the middle: Reasons for hindered growth among dairy groups of Haa district in Western Bhutan. Advances in Dairy Research 7 (226): 1-8.

Wangchuk, K., and J. Wangdi. 2015. Mountain pastoralism in transition: Consequences of legalizing Cordyceps collection on yak farming practices in Bhutan. Pastoralism: Research, Policy, and Practice 5 (10). https://doi.org/10.11 86/s13570-015-0025-x.

\section{Publisher's Note}

Springer Nature remains neutral with regard to jurisdictional claims in published maps and institutional affiliations.

\section{Submit your manuscript to a SpringerOpen ${ }^{\circ}$ journal and benefit from:}

- Convenient online submission

- Rigorous peer review

- Open access: articles freely available online

High visibility within the field

- Retaining the copyright to your article

Submit your next manuscript at $\boldsymbol{\nabla}$ springeropen.com 